\title{
Using Design Competencies to Define Curricula and Support Learners
}

\author{
FASS John ${ }^{\mathrm{a}}$; RUTGERS Job ${ }^{\mathrm{b}}$ and Chui Mo-Ling \\ a London College of Communication \\ ${ }^{b}$ OCADU, Toronto \\ ${ }^{c}$ London College of Communication \\ * j.fass@arts.ac.uk \\ doi: $10.21606 /$ dma.2017.578
}

This paper presents findings from design research related to a Design Competency Framework (DCF). The DCF is a visually-oriented system for developing curricula in design and is an example of the application of design research to design education. The DCF is divided into a set of sixteen categories including core skills, such as visualisation, and meta competencies such as synthesis. These are presented in the form of a matrix. We see three distinct advantages of using such a system. Firstly the DCF is personalisable at various scales such as individuals, units, courses, and programs. Secondly it is student centred - while we do not assume that design students are passive consumers of their own curricula in non-competency based design education we make the case here for student access to curriculum design processes. The DCF allows students to participate in the design of their own education. Finally, the DCF is resistant to imposition from above and as such questions the modes and institutional dynamics through which design courses come into being.

Design research, design competencies, design curricula, competency framework

\section{Introduction}

The current interest in design in both business (Kupp and Anderson, 2017; Kunitaki et al, 2016) and academia (Miller, 2017; Chamberlain and Mendoza, 2017) has produced many publications by academics, business leaders and design practitioners. In these books, papers and design thinking workshops the characteristics of design as a practice and as a way of thinking about the world is communicated to a mass audience with the aim of demonstrating how non-designers can acquire this strategic knowledge (Mootee, 2013; Manzini and Coad, 2015). While the values and characteristics of design are communicated to an ever increasing mass audience, these publications do not explore how design is learned in tertiary education (Rutgers et al, 2015). We are interested in asking how designers learn? and how should design education prepare people for their future 
practices in the many fields of design activity? What kinds of skills should they learn? and what should the overarching structure of a learning experience in design education look and feel like? The Design Competency Framework (DCF) is intended to address some of these questions through the lens of an organised matrix of competencies (Rutgers, 2015). This paper aims to set out a rationale and some examples of how the DCF can be useful, but does not intend to definitively establish a model for universal design education. It assumes that all learning experiences are contingent: on personal circumstances, on institutional prerogatives, and on local conditions of delivery and access.

Design as a professional discipline, as a cultural form, as a research field, and as an area of tertiary education is in a period of convergence (Deutsch, 2017; Watson, 2017; Self and Baek, 2017). Previously discrete design domains are starting to teach the same skills across multiple programs. For example, at LCC illustration, graphic design, interface design and interaction design all teach the core competency of sketching, and the higher level competency of coding. While design schools still divide their students into specific study areas and year groups, the design and development of design curricula in universities could be described as a kind of dark magic; ungrounded in evidence (Strauss, 2014), fulfilling institutional or marketing opportunity (Healey et al, 2014) instead of student needs (Havergal, 2015), and having unclear or untraceable trajectories over the three or four year period of study. The increasing marketisation of education in the UK, shown by a steady rise in tuition fees and consequent increase in student debt, has put art and design education under pressure to define exactly what it will provide a prospective student. The DCF suggests a way for design educators to articulate their curricula in a consistent and responsive way. The design competency framework matrix is shown below (Figure 1)

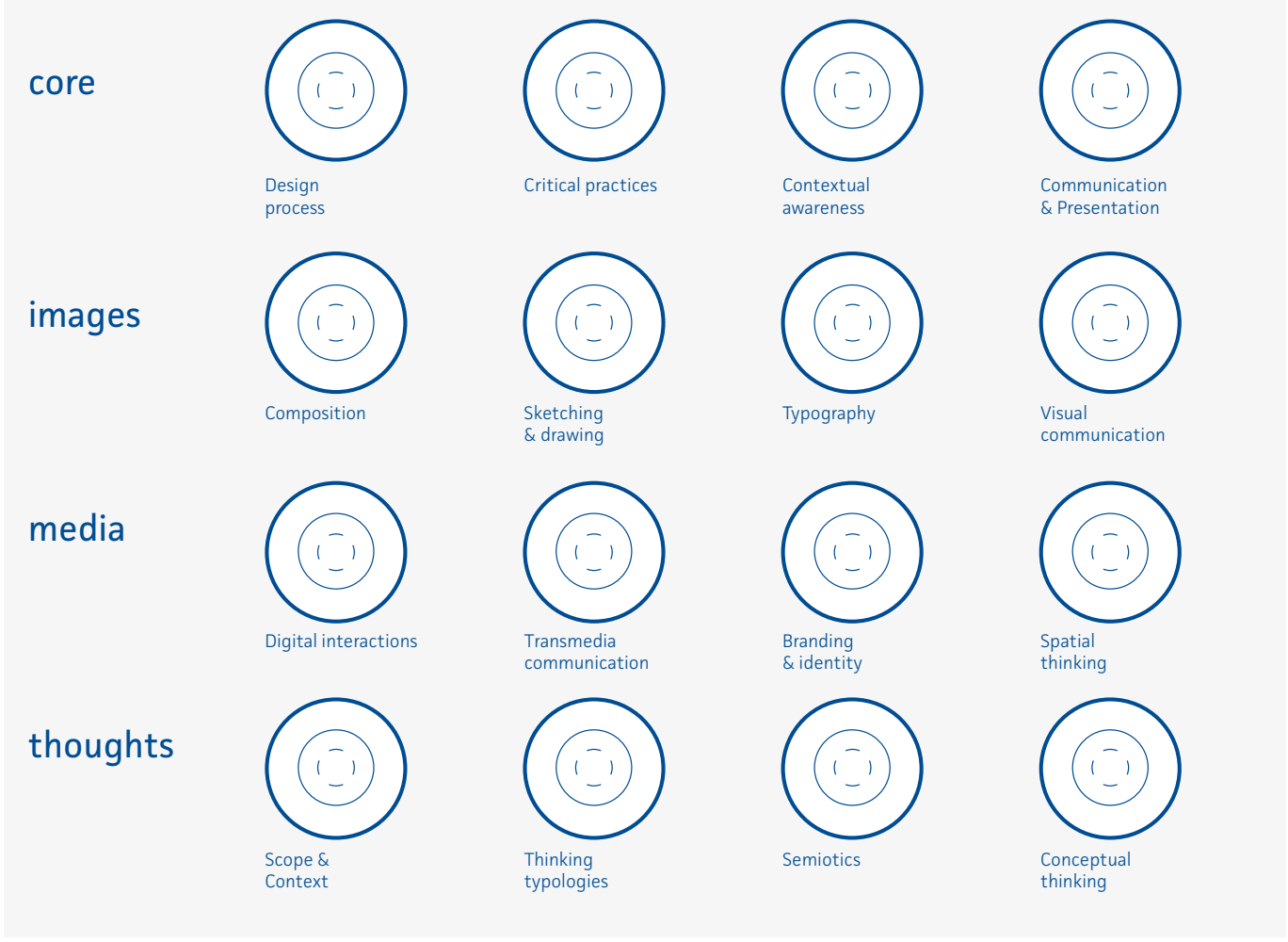




\section{Origins of the DCF}

The DCF came about from a need within the Industrial Design program at OCADU in Toronto where the program leaders set out to clearly articulate what students would be learning while studying there, what learning methods would be used, and what new knowledge they could hope to graduate with. The program is arranged around the acquisition of design competencies that develop alongside the expanding focus of the curriculum and the development of the student body as a group, and as individuals. We see three main advantages of this approach. First, it affords the development of curricula in design that are responsive to need by specifying competencies at multiple levels. Second, it is a personalisable framework that enables distinct models for different courses, navigable and deliverable by technical staff, academic leaders and students. Third, it allows input from learners themselves. It is not fixed in time, discipline or institution and contains the possibility for students to design their own trajectories through a program, contribute to the development of what they are taught, and even to redesign the curriculum anew every year should they wish. In other words, we do not assume that design students are passive consumers of their own curricula.

In an international team across two world-leading design universities, we have implemented the DCF in multiple ways. We have run three workshops at international design conferences including Cumulus 2017, and AIGA 2017. The intention at Cumulus was to determine the degree of flexibility in the DCF by asking design educators from all over the world in varied disciplines to design their own competency frameworks. The results revealed convergence between design programs, and a need for higher level meta competencies that cut across disciplines. The intention at AIGA was to provoke discussion in a design centred workshop about the design competencies of the future and reflect on the level of future-proofing the DCF allows. Results show the educators are perhaps not well prepared for the design of curricula that transcend traditional design boundaries to include say, bioscience or political activism. Within our respective institutions we have run workshops with academics and outside partners. The aims were to test the limits of accessibility of the DCF at an institutional level and to develop new or recently re-validated curricula. Results show how the DCF can both galvanise and support institutional systems for program development. Finally, we have used the DCF in the studio to elicit from students what skills they wish to learn and to allow them to track their own progress.

\section{Why competencies?}

Ennis (2008) defines a competency as 'the capability of applying or using knowledge, skills abilities, behaviours, and personal characteristics to successfully perform critical work tasks' (2008: 5). This definition incorporates how we have understood competencies in the DCF as more than technical ability or mastery of domain knowledge. Personal characteristics for example include cognitive, social and emotional attributes (Dubois, 1993; Lucia and Lepsinger, 1999) deployed by designers in the production of their work. The DCF thus emphasises competencies beyond traditional studio design skills. Boyatzis (1982) goes further to include the environments and relationships featured in a particular context and the motivations and perceptions an individual may have of themselves and their abilities. The DCF responds to this through its self assessment matrix that permits a developing picture of design competency to energy as a student progresses through a program. Another important aspect of Ennis' definition is its emphasis on the application of knowledge or ability. This is reflected in the DCF's insistence on design practice as the engine of learning and skills acquisition in design. 
In medical education competencies are seen as a way to place the student at the centre of the learning process (Harris et al., 2010). Like the DCF, students are required to monitor their progress toward stated goals. This allows the student to identify gaps in their knowledge and seek out learning experiences to fill those gaps. This process, and the models that facilitate it, is characterised by flexibility and the importance of self directed learning. An important aim of the DCF is to share responsibility for learning outcomes more meaningfully with students and thus ultimately do away with year groups by providing selectives chosen by students from a menu of options.

\section{Competency models}

A competency model is defined as 'a descriptive tool that identifies the competencies need to operate in a specific role or industry' (Ennis, 2008: 5). Sandwith et al (1993) identify the ranking of competencies in a hierarchical model as integral to the concept of a competency framework, the DCF follows this pattern. The argument in favour of organising competencies in a framework or model structure is that it allows for adaptation and customisation of a program of study (McClelland, 1973; Spencer and Spencer, 1993).

Using a competency based framework means working backwards from which competencies a program wishes to furnish its students with towards the levels of competency expected at what points on the program of study. Learning experiences and materials can then be devised to fulfil these needs at specific points in the learning journey. Describing competency based medical education Harris et al., (2010) show how 'using a competency based framework... and working backward to build enabling competencies in the undergraduate curriculum may provide an authentic curriculum focused on the qualities and attributes required' $(2010 ; 646)$. In addition they identify a weakness of their curricula that also often applies to design. 'A clearly articulated framework of practical, real world objectives provides a rare opportunity for students to develop a clear pathway toward relevant competencies. Many previous curricula have relied on a layering of experiences that do not always build on one another', (2010: 647). Of course medical education is not the same as design education and there may sometimes be a strong argument for the layering of learning experiences in design but the argument we would like to develop is that these experiences should be observably directed towards a set of definable goals that progress through the curriculum.

\section{Competency models in design education}

Competency models in art and design education have been a way to gain equal status with subjects already using competency models, such as literacy and mathematics (Haanstra, 2013). In a review of competency models in art and design (ENVIL, 2015) certain characteristics are evidenced, these are divided into responding and making. The former includes contextualising design work in relation to history and cultures, and students reflecting and assessing their own and others' work. Making includes applying media, techniques and processes, using knowledge of structures and functions, and selecting and evaluating a range of subjects, symbols and ideas. We can see that there are some competencies that may be distinctive in art and design, i.e. application of subject knowledge to material processes, higher level awareness of the social and political meanings of systems and structures, and positioning within the cultures and histories of creative practice.

Design education does not only happen in universities and arts schools. For example, Business Innovation Factory (BIF) a design agency specialising in business development has developed a 
competency model (BIF, 2017) of its own intended to guide its employees through a career in experience design. Their 'career competency framework' is organised around core competencies that correspond to individual, project, team, and organisation levels of work activity and thus scale through the company. The model specifies what advancement through the company implies in terms of competency for an experience designer and features many elements, such as visual communication and story telling or self-direction and evaluation that would be expected in a design program competency model.

\section{Theoretical background}

We use the term design competency to denote learning outcomes from the cognitive domain (thinking), the psychomotor domain (making), and the affective domain (feeling). Thus for us a design competency is defined as the knowledge (as it relates to thinking, cognition); the skills (doing, making); and the behaviours (feelings, attitudes, motivations) students need to acquire. We seek to integrate these separate elements of Bloom's (1959) taxonomy and suggest that design is an area of human activity where the cognitive, the psychomotor and the affective domains are successfully combined (Qamar et al., 2016; Berk, 2016). An example is a student designing a system for a palliative care home. She tries to imagine what it is like to lie in a hospital bed by role playing, she reviews the available literature and practice relevant to the topic, and she makes design prototypes at increasing levels of resolution in order to develop and communicate her ideas. In this way she combines respectively her affective capability to empathise with people and situations, her cognitive ability to interpret and synthesise existing sources, and her psychomotor ability to make things and test them. Schön (1992) describes this as reflection in action it is 'a reflective conversation with the materials of a design situation in which designers interact with their immediate design representations' (Schön, 1992: 67). Traditionally in education these domains are treated separately. Cognitive abilities are acquired in universities through formal learning experiences such as reading, essay writing, lectures and seminars. Technical education by contrast focused on the psychomotor domain by teaching mastery of a technical skill such as machining or millinery. Training of a psychologist in turn would also focus on affective abilities in the context of communicating with patients. In design, we recognise that it is necessary to authentically combine all these ways of being, doing and acting and suggest that a competency framework is a good way of doing so because the overlaps are made explicit at every stage of the program.

The many ways of doing design include sketching, diagramming, body storming, visual storytelling and spatialisation and provide a rationale for the many types of learning experience in design education. These methods are also explicitly exposed as design competencies in the DCF matrix. Developing different types of intelligence is an essential part of training as a designer, this is reflected in how analytical thinking, visual thinking, spatial thinking, temporal thinking, and conceptual thinking are embedded in the DCF. This variation in thinking styles draws on and demonstrates Gardner's (1983) theory of multiple intelligences with include the visual-spatial, the bodily-kinesthetic, and the interpersonal. The DCF is thus an attempt to incorporate these different types of intelligence into design curricula in a way that can be clearly evaluated and communicated.

Designers know that solutions are rarely completely new or original: they are usually a recombining of existing ideas into new configurations. This implies that design consists of crafting new relationships between elements from a personal reserve of heuristic understandings. Martin (2007) calls this integrative thinking, which he calls 'a process of discipline and synthesis' (2007: 7) whereby the connections and relationships between two opposing models of a situation are combined into a third that features elements of the first two but is stronger, more valid, or more relevant to a given 
context. The competencies necessary to do this kind of synthesis in design involve adapting to different thinking typologies, developing contextual awareness and sensitivity to the demands of various materials.

In summary, the DCF seeks to integrate Bloom's taxonomic categories through reflective practice involving cycles of experimentation, iteration, and evaluation. These steps feature different ways of thinking through a design situation, such as visual or temporal, to arrive at a new synthesis of meaning and context. The following section will report on two case studies, the first focuses on the development of a new curriculum, the second on student trajectories through an undergraduate design program. Finally, we position a competency approach as being in sympathy with the aims of West et al (2017) with regard to how curriculum design involves refining materials and themes over time, and developing methods of evaluation. In addition, we acknowledge that there are many different approaches to curriculum design such as the standards based ideas of Magee (2017) and the need to articulate relationships (including their limitations) between what Dalziel (2015) calls conceptual maps, frameworks, and practice in learning . We have found that a competency based model is well suited to the experiential and embodied learning that takes place in design schools and suggest it as way of implementing the concerns expressed by the Larnaca Declaration (Dalziel et al, 2013).

\section{Design and business at OCADU}

This section reports on the process of designing a competency-based curriculum in higher education in Toronto, Canada. We present the results of a faculty workshop that aimed to envision what a new BA program in design and business could look like at OCADU.

Fifteen participants were drawn from OCADU faculty, McMaster University, and external partners. Participants were consciously included to reflect the range of experience and opinion in the relevant departments, this is thus an example of purposive sampling since we interested in a specific group of faculty members. The methods used included visual annotation of the DCF matrix, group discussion, diagramming and card sorting. In the initial task three groups of faculty members were asked to identify competencies for three different student personas using card sorting and personas.

Personas are considered to be aggregated individual profiles, derived from prior research. They are used in design as a way of representing different user types and have been extensively deployed in human centred design and interaction design (Getto and Amant, 2015; Kunur at el., 2016). Personas were divided into social entrepreneurs, business start ups, and design project managers (Figure 2). These were developed to reflect the range of applications, and the stated interests of potential applicants.

\section{Business Start Ups}

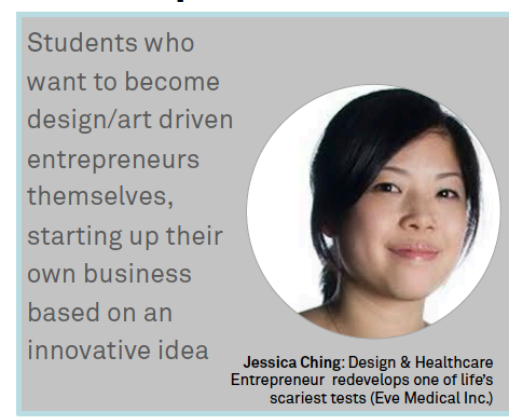

\section{Social entrepreneurs}

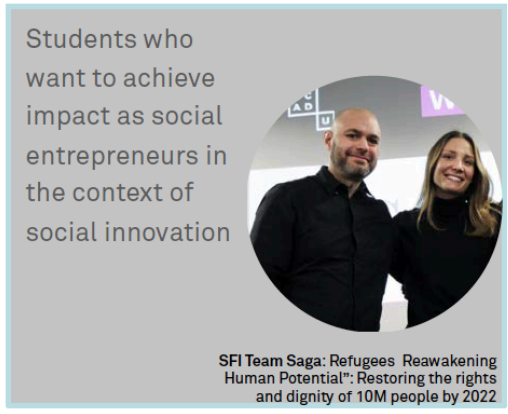

\section{Design project Managers}

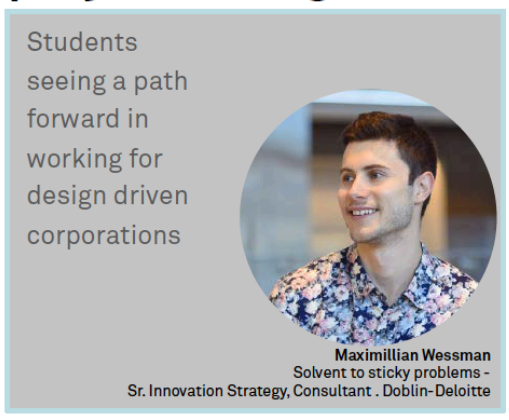


The next step involved brainstorming the potential competencies of the student personas. Participants started by first card sorting, then adding and rephrasing their own ideas prior to arranging them on a table visible to their particular persona group. Next it was necessary to categorise those competencies and map them to the DCF matrix. The matrix is limited to sixteen separate competencies, this number was chosen as we have consistently found it to enable sufficient detail in the curriculum without over-specifying a program of study. In this way at the end of the first phase of the workshop participants had created three detailed competency matrices, one each for the three personas (Figures 3, 4, \& 5).
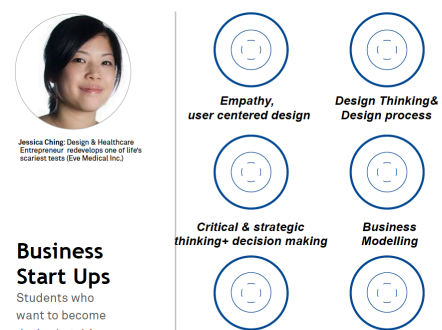

Start Ups

Start Ups
Students who
want to become

want to become
design/art driven
entrepreneurs
themselves,

entrepreneurs
themselves,
starting up their
own business
based on an
innovative idea
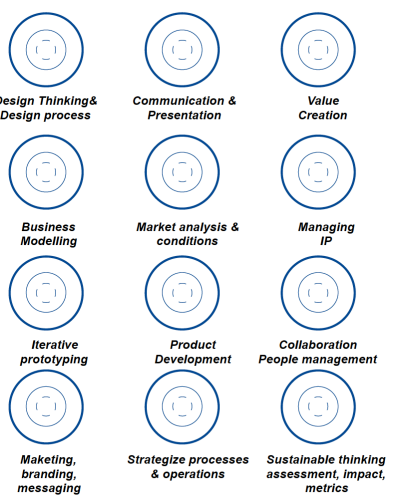

\begin{tabular}{cc}
$\begin{array}{c}\text { Strategize processes } \\
\text { \& operations }\end{array}$ & $\begin{array}{c}\text { sustainable thinking } \\
\text { assessment impac } \\
\text { metrics }\end{array}$ \\
\hline
\end{tabular}
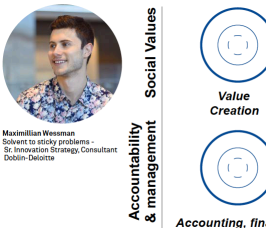

Design

project

Managers

Students
seeing a path

seeing a path
forward in
working for
design driven

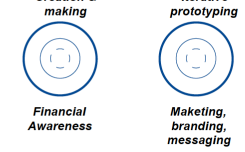

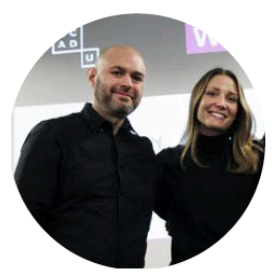

SFI Team Saga: Refugees Reawakening Human Potential": Restoring the right
and dignity of $10 \mathrm{M}$ people by 2022

\section{Social} entrepreneurs

Students who want to achieve impact as social entrepreneurs in the context of social innovation
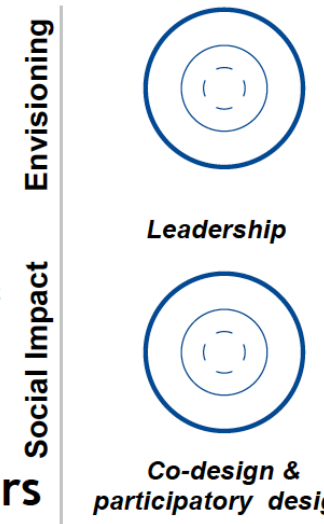

Leadership

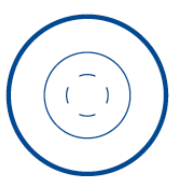

Co-design \& participatory design
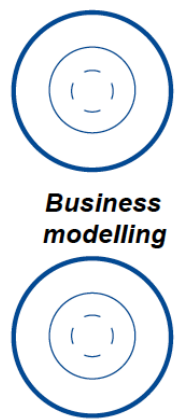

Systems

Thinking

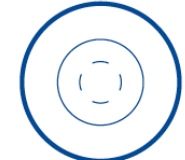

Foresight \& strategic thinking

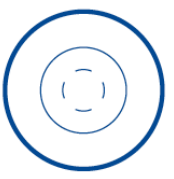

People
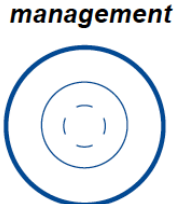

Project

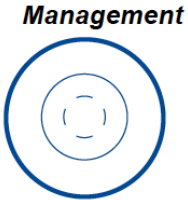

Design Thinking

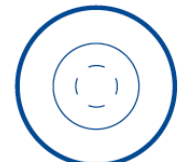

Technology Literacy

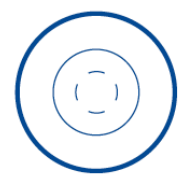

Empathy \& user insights

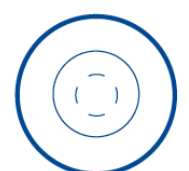

(story telling) Marketing Branding, messaging

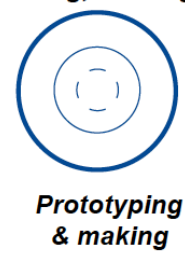

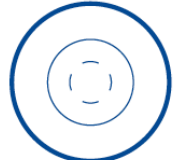

Value

Creation

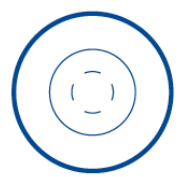

Collaboration \& teamwork

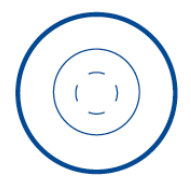

Communication \& presentation

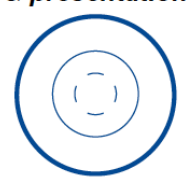

Product, service \& systems design 
The next step in this phase was to integrate the three separate matrices that arose from the individual students' personas into a single competency matrix (Figure 6). This was done by identifying competencies common across the three matrices. The aim here was to derive a comprehensive set of competencies around which to build a curriculum.

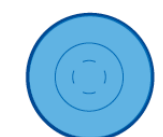

Design Thinking \&
Design process Design process

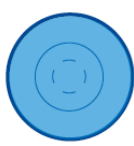

Value
Creation

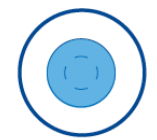

Co-design \&
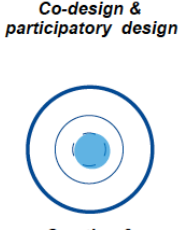

Creation \&

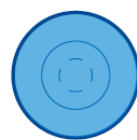

Empathy \&
user insights

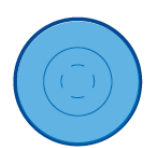

Sustainable / systems
thinking

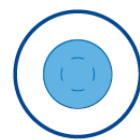

Business

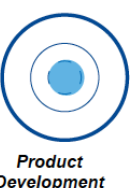

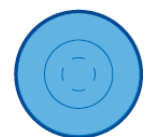

Iterative prototyping
\& making

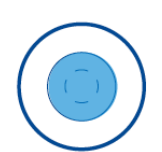

Accounting, financial
administration

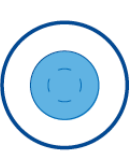

Strategize processes

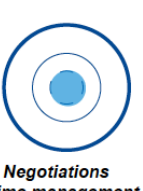

Negotiations
\& time management

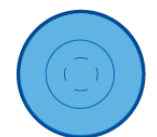

Communication \&
Presentation

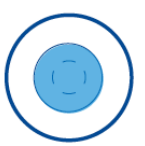

Collaboration \&
teamwork

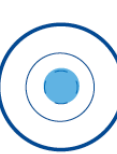

Product, service

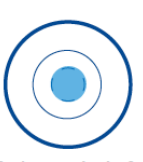
conditions

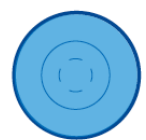

Leadership \&

People Management

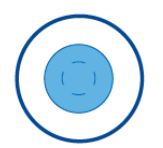

(story telling) Marketing
Branding, messaging

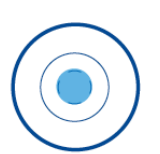

Ethics

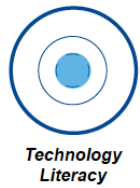

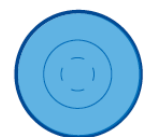

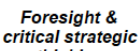

critical strategic
thinking

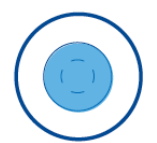

Project
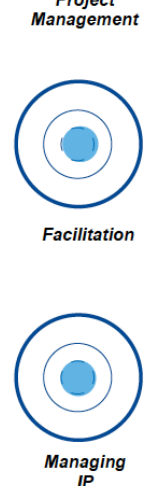

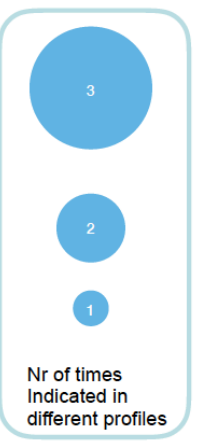

Figure 6 Aggregated competency matrix

Phase two of the workshop required participants to follow a similar exercise related to their respective personas but this time to focus on meta-competencies. Meta competencies (Figure 7) are defined as those that involve students learning at a higher level of abstraction. They are the most valuable, long lasting and future-proof competencies that students acquire, but also the hardest to measure and codify, and therefore difficult to implement at curriculum level. For the new design and business degree meta-competencies include; creative confidence, intrinsic motivation and managing complexity.

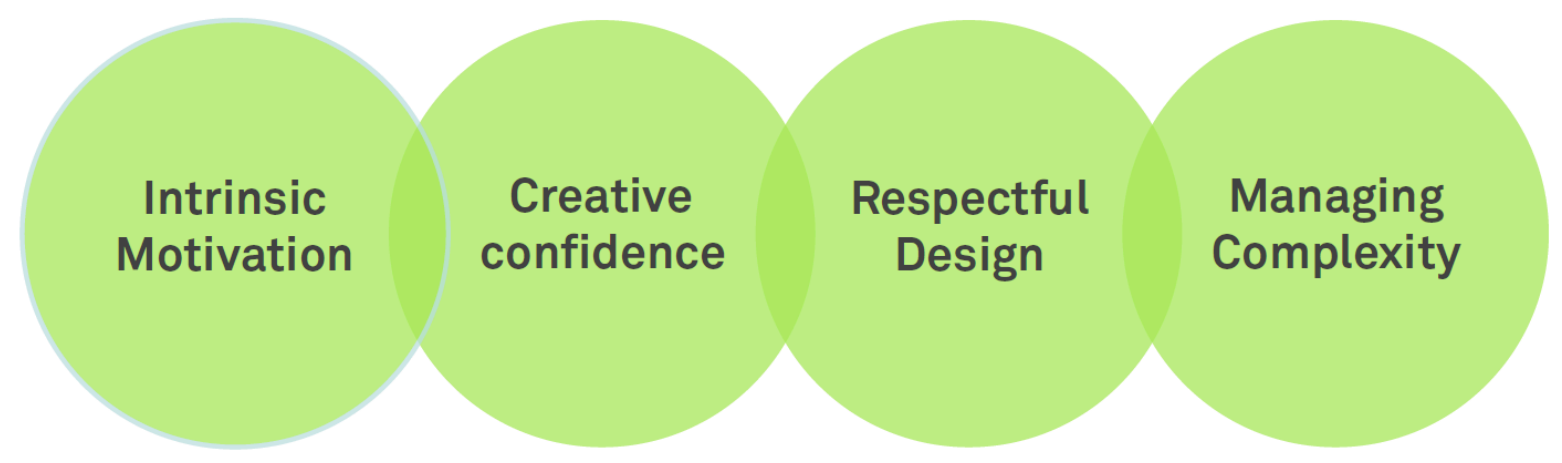


The final phase of the workshop involved all participants working together to identify pedagogical assets across OCADU and beyond (Figure 8). This figure is included to demonstrate how the process of identifying assets involves rough sketching and unresolved collaborative diagramming familiar to designers from brainstorming and prototyping processes.

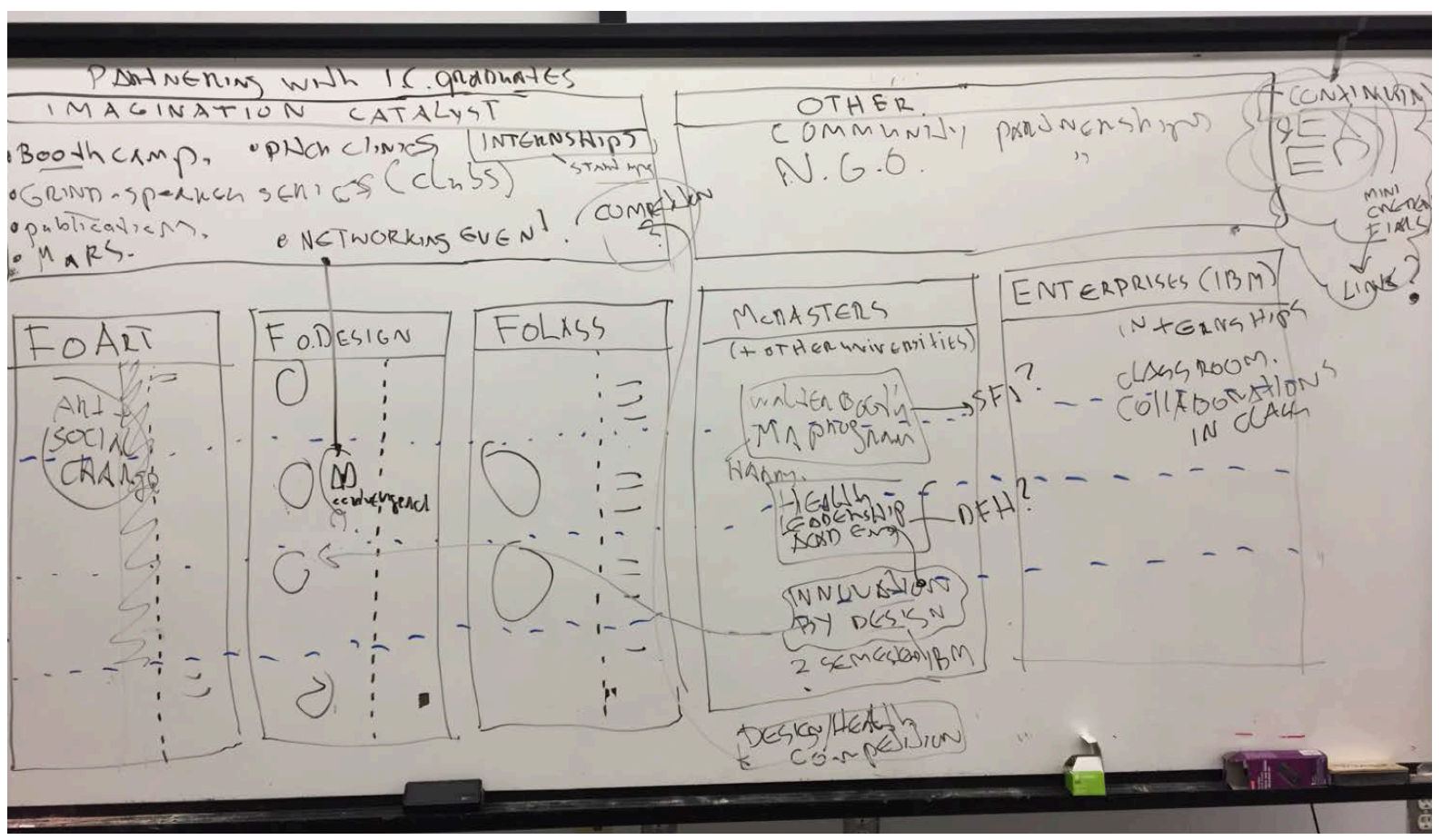

Figure 8 Planning with assets

This meant accounting for the complementary priorities of project partners and how they might unfold over time in the context of a series of learning encounters and varied learning experiences. An important finding here is that visual mapping enables points of overlap to emerge and corresponding opportunities for collaboration and specialisation to be mapped to overall aims of the university and the elicited student competencies.

Using the DCF for curriculum development revealed its effects as a design artefact in itself. These effects can be seen as enabling externalisation, categorisation, specification and planning.

\section{Externalising}

Participants in the workshop were chosen because of their involvement, experience and expertise in design and business education. Their knowledge in these areas is tacit, implicit knowledge, built up over years of teaching and practicing in their respective areas of activity. The DCF was seen to structure the externalisation of this knowledge by focusing thoughts in written form first on small cards so that they could be read by all members of a group and then transposed to the DCF matrix sheet.

\section{Categorising}

Transposing the results of the brainstorming step, where many ideas emerge in a relatively unstructured way, involves deriving categories from the resulting data. The DCF matrix, a paper sheet printed with a visual representation of the DCF as a series of circles arranged in a grid, affords data reduction. The associated need for categories is enforced by constraining the possible 
competencies to sixteen. Thus the DCF was seen to support the identification of categories as well as individual competencies.

\section{Specifying}

The resulting set of competencies, arranged according to four categories and allowing for different levels of expertise, were then used to specify the design and business BA program. The process of specifying what the students on a design program would be required to learn involves other institutional factors such as marketing, portfolio development, and departmental profile but in an initial workshop scenario the DCF showed how it can be used to specify the overarching logic for the curriculum of a design and business undergraduate degree.

\section{Planning}

The process of; externalising tacit knowledge into individual competencies, deriving categories from them, then specifying the content of a program according to where the competencies fall into categories allows for planning across a number of axes such as duration of study, learning spaces, and partner organisations. In the case of the OCADU proposed design and business program, planning involved integrating multiple stakeholders such as faculty members, a partner institution, and industry collaborators. The DCF allows this process by making it clear what students would be learning and when.

The way the DCF provides for externalising, categorising, specifying, and planning is through visual mapping, synthesis, and collaborative sharing. The advantages of visual representation of complex systems are well covered elsewhere (Larkin and Simon, 1987; Mclnerny et al., 2014) and the DCF was shown to support findings that demonstrate the ways visualisation helps in assigning categories of information, providing an overview of systems with multiple elements and how these might change over time. Finally, the DCF was shown to support collaborative working in groups from four members up to fifteen by scaling to different levels i.e. from a single competency card to a fully specified matrix. Working together and sharing the results of the group work was shown in the OCADU workshop to be enhanced by the way the DCF allowed participants to input their contributions, and how it allowed for plenary sharing.

\section{Information and interface design interactive prototype}

This case study reports on the design and development of a prototype online version of the DCF. The aims of the online digital prototype are to allow design students to track their own progress through a course of study, to enable self assessment, to provide detail about what constitutes a competency on IID, and to output a personal competency profile at any given stage of the program. The case study was conducted as part of an undergraduate degree in information and interface design (IID) at London College of Communication (LCC). Seventeen first year students were asked to complete a blank DCF matrix sheet, writing in the competencies they believed should be taught as part of the program (Figure 9). The intent was to explore the possibility that students could design their own degree, participate in program development, and challenge their position in academic management as compliant consumers of the curriculum.

The resulting contributions were aggregated using the same method as case study one to derive an overall competency matrix for the program (Figure 6). This is not seen as a fixed pattern, but is 
intended to be open to change and continuous input. Students are encouraged to fill out the aggregated program competency matrix after completing each unit of study as a means of evaluation. An end of academic year review would thus reveal what they felt they had learned and to what level. On graduation, their final sheet would provide a guide to their overall abilities and help position themselves and their competencies for a post university creative life.

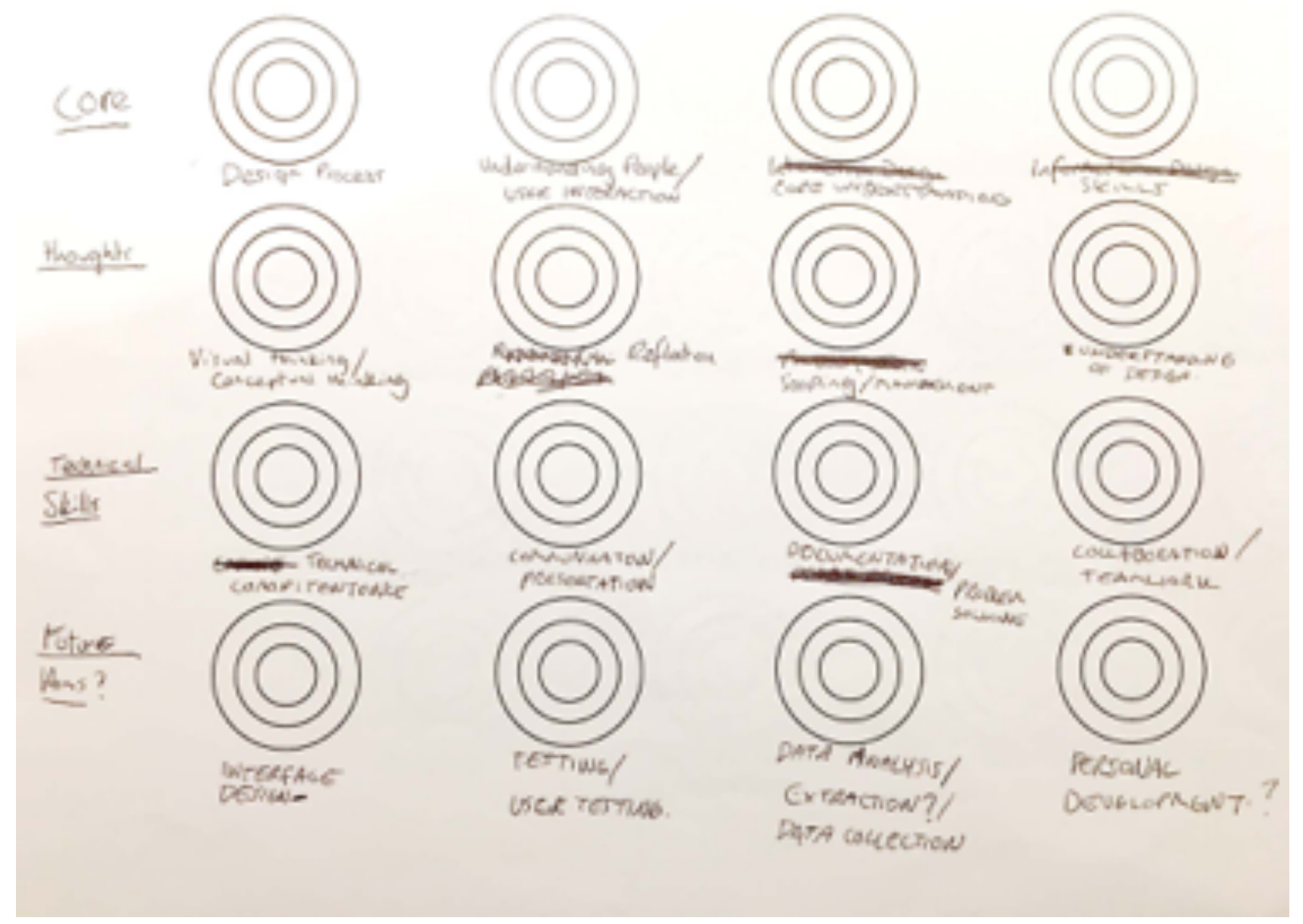

Figure 9 Students decide program competencies

The digital version of the DCF reproduces the original matrix but enhances its possibilities for interaction by allowing students to select and save the competencies they input, whilst also contextualising the model, the program, and the particular unit students are working on. The resulting matrix reveals what competencies have been learned to what level of mastery, allowing for basic controls such as saving and editing. 


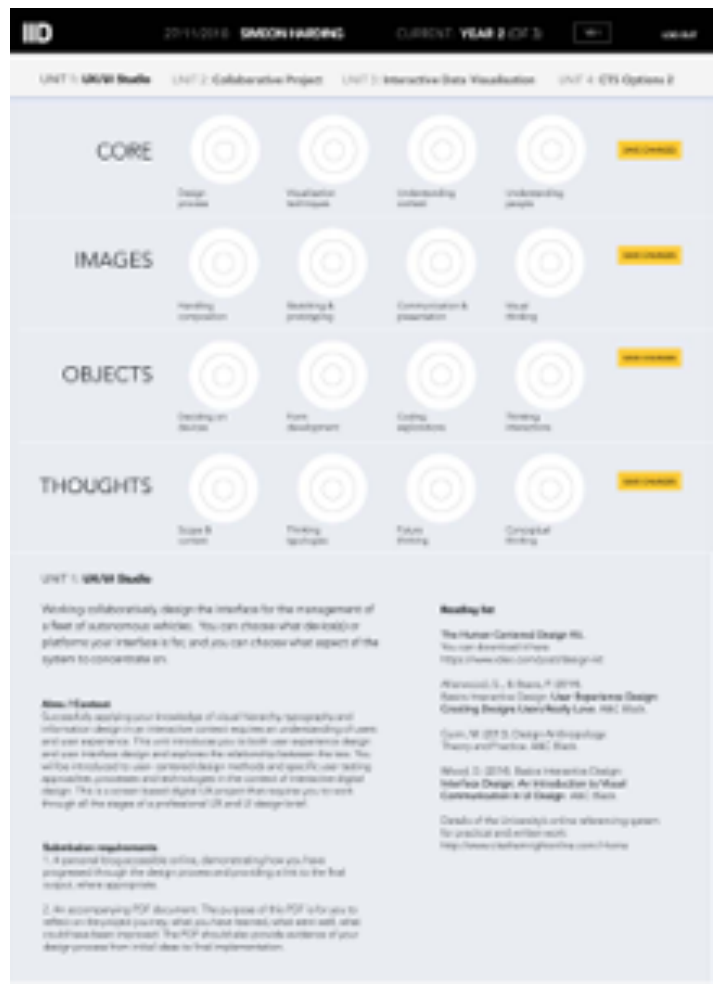

Figure 10 Interactive matrix

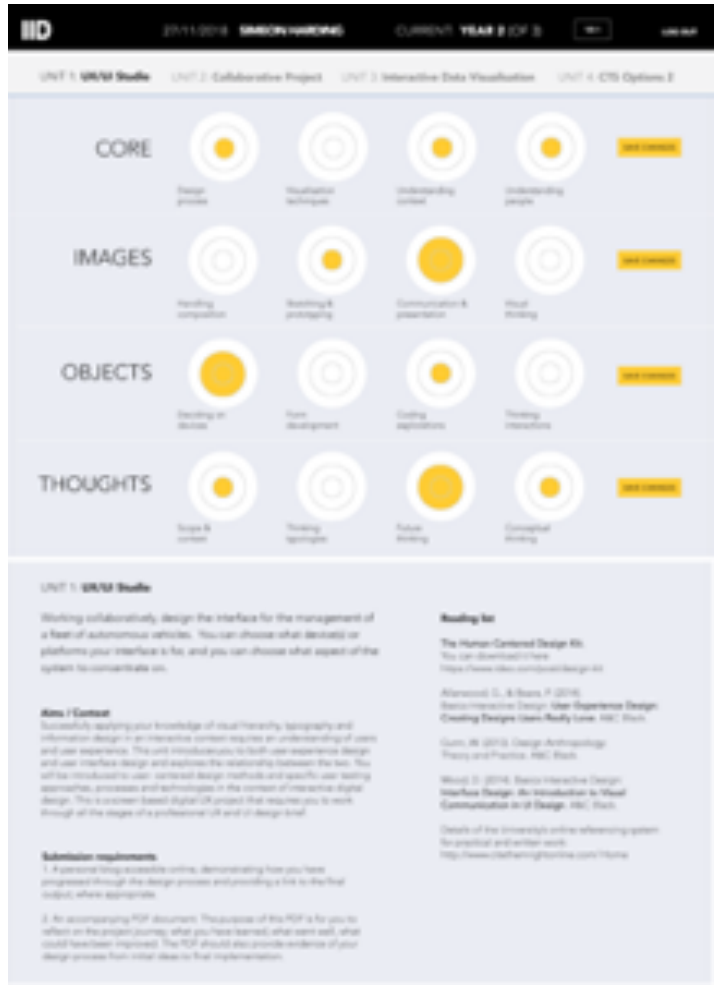

Figure 11 Completed interactive matrix

The system allows for an annual overview by collating the individual matrices from each unit over a year of the program. Students, tutors, lecturers, (and ultimately the university as a whole) are often assessed according to the levels of students attainment both between units, and over the academic year. Providing an annual overview (Figure 10) thus also provides a representation of individual achievement from a student-centred perspective, concentrating on the characteristics of student competency acquisition (Figure 11). During this phase of development of the prototype students expressed the wish for the possibility to grade themselves, but pointed out the necessity to see completed competency profiles from other students in order to give the correct weighting to their level of mastery. To answer this need, clicking on a competency label brings up an explanation of what it consists of (Figure 13). The next stage for this element would be to give an explanation of how the various levels of mastery are derived. 


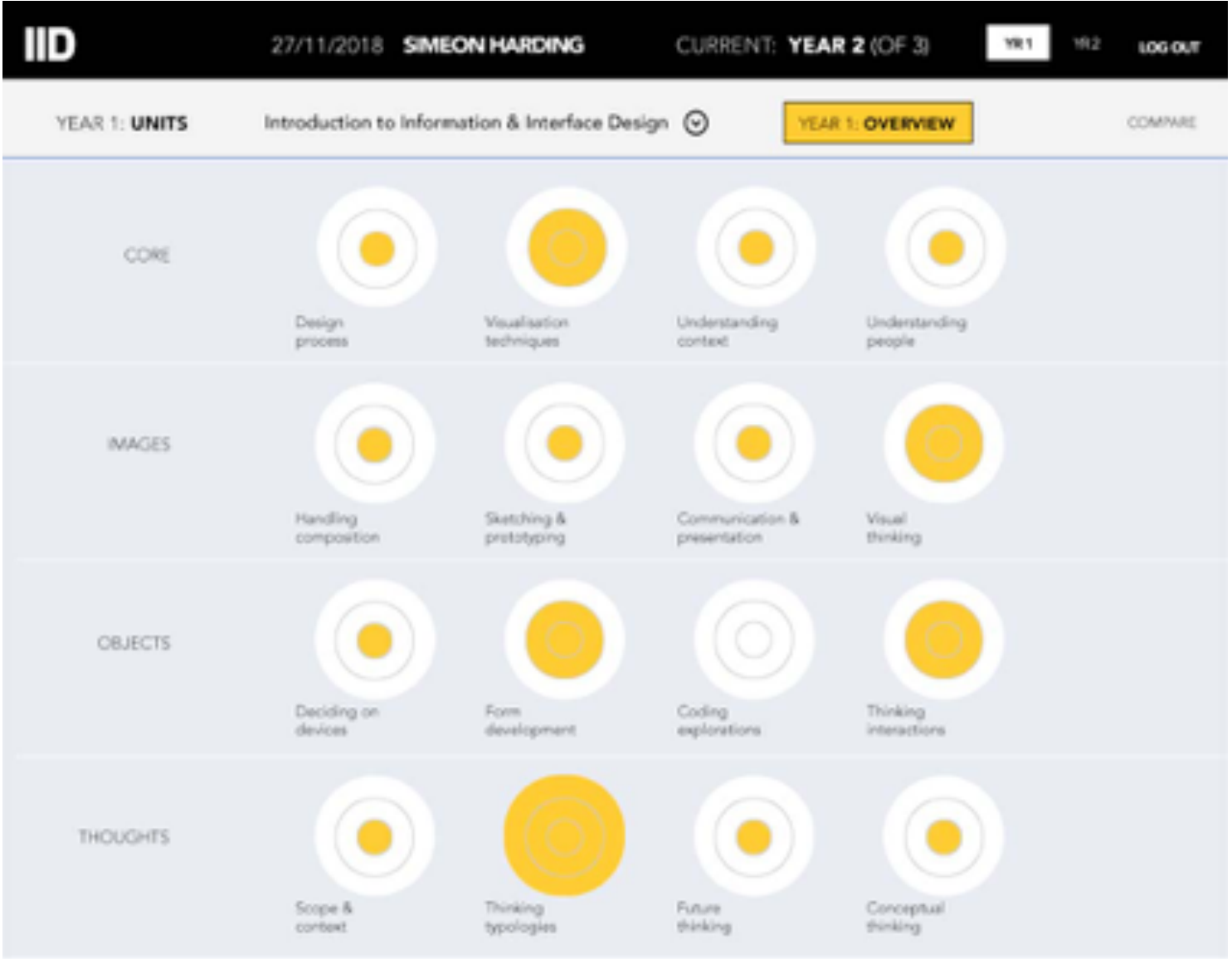

Figure 12 Annual overview matrix

While still in an early stage of development, student feedback suggests the online DCF system (Figure 12) has some advantages over the paper version, as a tool for autonomous learning management, i.e. by tracking progress through the program, by explaining the details of competencies and levels, and thus enabling self assessment. The system also provides the opportunity for reflection and comparison via a visual gap analysis, and includes the possibility for outputting a shareable personal competency profile. The ways it does this include, visualisation, interaction, scaleability, and democratisation. 


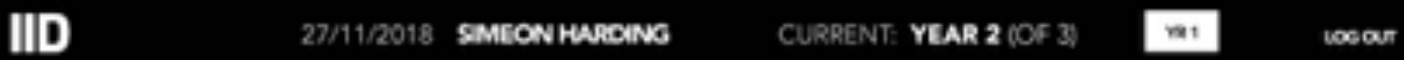

UNT 1: UXYUI Studio

VISUALISATION TECHNIQUES: User flow
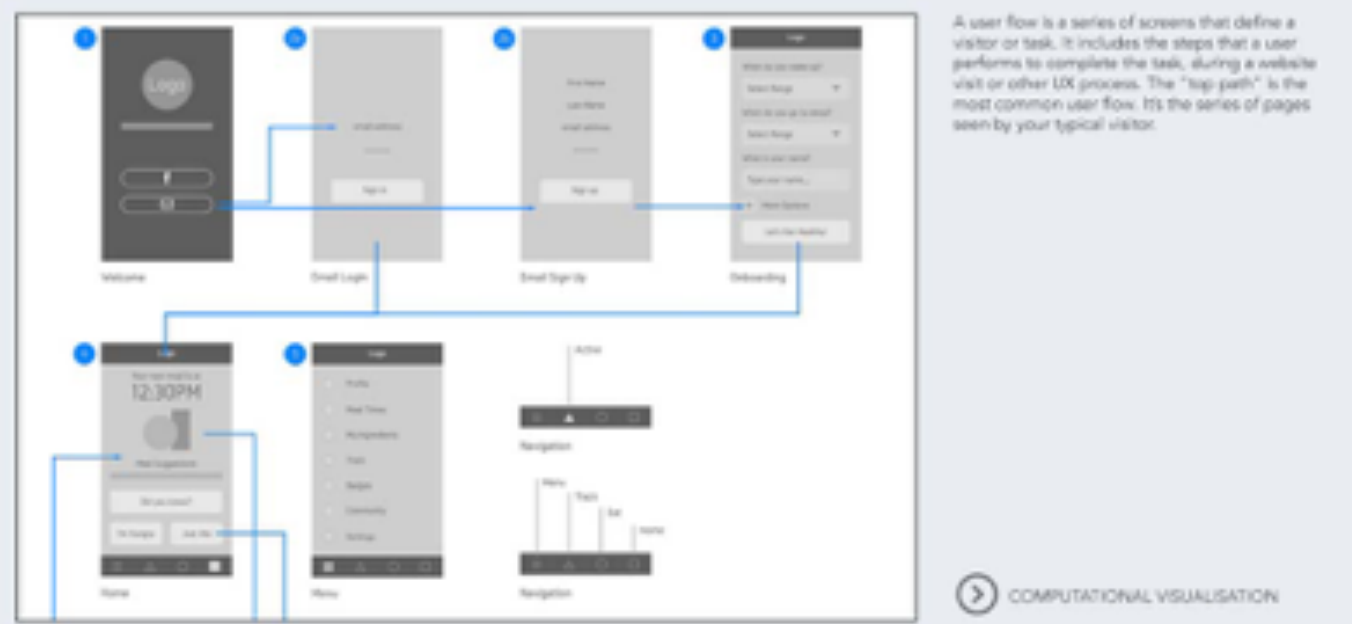

(D) conutationu vesusenton

Figure 13 Annual overview matrix

progress through the program, by explaining the details of competencies and levels, and thus enabling self assessment. The system also provides the opportunity for reflection and comparison via a visual gap analysis, and includes the possibility for outputting a shareable personal competency profile. The ways it does this include, visualisation, interaction, scaleability, and democratisation.

\section{Visualisation}

The online DCF prototype represents visually the way a student proceeds through the program, resulting in a trajectory signature. This is a visual record of what competencies they have achieved at what level of mastery at what point in the course. The value of this representation to teachers and students are that it allows the student to see how they have oriented themselves respective to the discipline and adds to their ability to position themselves on graduation for what they might wish to do next. Another valuable insight it affords is to teachers and academic managers about what competencies students are achieving and at what level, and therefore what gaps may exist in learning outcomes and experiences. Making attainment levels visually transparent between students and teachers also enables a flattening of the information hierarchy in the institution.

\section{Interaction}

Using the online DCF involves interacting with it by; selecting levels of mastery of separate competencies by clicking the concentric rings, saving the resulting profile, changing the level as a result of comparison with peers or through tutor feedback, then updating the profile. Interactions also allow for examination of competencies by accessing units, years, people, and the deeper 
explanations of competencies. Additional features could include sending a profile via email, zooming out to show comparison between all units of the program, and matching personal profiles to job competency profiles. Finally, the interactive version of the DCF make it tractable and navigable at multiple levels in a way not possible with paper sheets.

\section{Scaleability}

Capturing and representing the micro level competency achievements of an individual student over a single ten week unit, and also allowing for a macro view of all students' competencies across all units of a three year degree means the online DCF has the potential to scale throughout the years of study and beyond as graduates pursue further study or professional training. It also means the program as a whole can be assessed according to how well its graduates have mastered the competencies it purports to teach. This ability to scale from personal to institutional level whilst maintaining a student-led structure has implications for how the DCF may be used to further democratisation and accessibility.

\section{Democratisation}

By consciously promoting self awareness of learning attainment, representing self management of progress through a degree program, and allowing for self assessment, the online DCF system hopes to promote student-inclusive curriculum design. Including students in the design of their own curriculum by eliciting the competencies and the broader categories they sit within we hope to lessen the distance between academic management bodies such as quality control officers, and departmental portfolio development. While we do not suggest that all curriculum design should be done by potential and current students, and that there are existing mechanisms such as student representation on course validation boards, we promote the values of inclusiveness inherent in a method and instrument that cedes some of the determining power of decision making to the people it will most effect in a way that involves reflection in the design studio itself, using a visual model.

\section{Conclusion}

In conclusion we suggest that the use of a Design Competency Framework can help at the start of a curriculum process. For example, when an institution wishes to devise a new design curriculum; academic management, course leaders, teachers and students can collaborate on what the program should teach, to what level, and at what point. The DCF provides a template and a process for how this could be done, not necessarily replacing existing systems but complementing them in a way that welcomes inclusiveness and involves the primary stakeholders. When a program is underway, the DCF is a means of making individual progress visually and interactively accessible to students and teachers through visual externalisation. The DCF also supports categorisation, which both permits specification of a curriculum and how to update it in response to identified needs. By encouraging and framing academic self-management the DCF supports learning autonomy and self awareness of skills and abilities. The integration of cognitive, psycho-motor and affective abilities in the pursuit of design making supported by the DCF holds the possibility for a high degree of flexibility and responsiveness necessary in a time of uncertainty and rapid change in design education. Well defined and rigorously derived competencies also have a longer shelf life (ten years or so) than the rapidly changing needs that emerge from short term institutional planning. Future work includes investigating the use of the framework through the duration of a degree program, evaluating its effectiveness as an instrument of academic self management, and exploring how it might adapt to varied cultures of institutional decision making. 


\section{Referencing}

Ashworth, P. D., \& Saxton, J. (1990). On 'competence'. Journal of further and higher education, 14(2), 3-25.

Berk, S. (2016). Designing for the Future of Education Requires Design Education. Art Education, 69(6), 16-20.

Biggs, J. B. (2011). Teaching for quality learning at university: What the student does. McGraw-Hill Education (UK).

Bloom, B. S.; Engelhart, M. D.; Furst, E. J.; Hill, W. H.; Krathwohl, D. R. (1956). Taxonomy of educational objectives: The classification of educational goals. Handbook I: Cognitive domain. New York: David McKay Company.

Boyatzis, R. E. (1982). The competent manager: A model for effective performance. John Wiley \& Sons.

Buitrago Flórez, F., Casallas, R., Hernández, M., Reyes, A., Restrepo, S., \& Danies, G. (2017). Changing a Generation's Way of Thinking: Teaching Computational Thinking Through Programming. Review of Educational Research.

Chamberlain, L., \& Mendoza, S. (2017). Design Thinking as Research Pedagogy for Undergraduates: Project-Based Learning with Impact. Council on Undergraduate Research Quarterly, 37(4).

Dalziel, J. (2015). Reflections on the art and science of Learning Design and the Larnaca Declaration, in The Art and Science of Learning Design, Eds. Maina, Craft and Mor, Technology Enhanced Learning, Vol. 9, Sense Publishers.

Dalziel, J., Conole, G., Wills, S., Walker, S., Bennett, S., Dobozy, E., Bower, M. (2013). The Larnaca Declaration on Learning Design, retrieved from www.larnacadeclaration.org.

Deutsch R., (2017). Convergence: The Redesign of Design, John Wiley \& Sons.

Ennis, M. R. (2008). Competency models: a review of the literature and the role of the employment and training administration (ETA) (pp. 1-25). Office of Policy Development and Research, Employment and Training Administration, US Department of Labor.

Fogg, C. D. (1999). Implementing your strategic plan: How to turn" intent" into effective action for sustainable change. AMACOM Div American Mgmt Assn.

Gardner, H. E. (2000). Intelligence reframed: Multiple intelligences for the 21st century. Hachette UK.

Getto, G., \& Amant, K. S. (2015). Designing globally, working locally: Using personas to develop online communication products for international users. Communication Design Quarterly Review, 3(1), 24-46.

Haanstra, F. (2013). Research into Competency models in Arts Education, BMBF International Perspectives of Research in Arts Education workshop.

Harris, P., Snell, L., Talbot, M., Harden, R. M., \& International CBME Collaborators. (2010). Competency-based medical education: implications for undergraduate programs. Medical Teacher, 32(8), 646-650.

Havergal, C. (2015). Should students be partners in curriculum design?, TES.

Healey, M., Jenkins, A., Lea, J. (2014). Developing research-based curricula in college-based higher education, HEA.

Kupp, M., Anderson, J., \& Reckhenrich, J. (2017). Why Design Thinking in Business Needs a Rethink. MIT Sloan Management Review, 59(1), 42. 
Kunitaki, S, (2017). The Non-Designer's Guide to Design Thinking, Biotope Publishing.

Kunur, M., Langdon, P. M., Bradley, M. D., Bichard, J. A., Glazer, E., Doran, F., Loeillet, J. J. (2016). Reducing Exclusion in Future Cars Using Personas with Visual Narratives and Design Anthropology. In Designing Around People (pp. 269-277). Springer, Cham.

Larkin, J. H., \& Simon, H. A. (1987). Why a diagram is (sometimes) worth ten thousand words. Cognitive science, 11(1), 65-100.

Magee, J. P. (2017). How Can Human-Centered Design Be Used To Implement A Teacher-Designed, Standards-Based Curriculum? digitalcommons.hamline.edu

Manzini, E., Coad, R. (2015). Design, When Everybody Designs: An Introduction to Design for Social Innovation, MIT Press.

Martin, R. L. (2009). The opposable mind: Winning through integrative thinking. Harvard Business Press.

McClelland, D. C. (1973). Testing for competence rather than for" intelligence.". American psychologist, 28(1), 1.

Mclnerny, G. J., Chen, M., Freeman, R., Gavaghan, D., Meyer, M., Rowland, F., Hortal, J. (2014). Information visualisation for science and policy: engaging users and avoiding bias. Trends in ecology \& evolution, 29(3), 148-157.

Miller, P. N. (2017). Is "Design Thinking" the New Liberal Arts?. The Evolution of Liberal Arts in the Global Age, 167.

Mootee, I., (2013). Design Thinking for Strategic Innovation: What They Can't Teach You at Business Or Design School, John Wiley \& Sons.

Qamar, S. Z., Kamanathan, A., \& Al-Rawahi, N. Z. (2016). Teaching product design in line with Bloom's taxonomy and ABET student outcomes. In Global Engineering Education Conference (EDUCON), 2016 IEEE (pp. 1017-1022). IEEE.

Rodriguez, D., Patel, R., Bright, A., Gregory, D., \& Gowing, M. K. (2002). Developing competency models to promote integrated human resource practices. Human Resource Management, 41(3), 309-324.

Rothwell, W. J. (2002). The workplace learner: How to align training initiatives with individual learning competencies. AMACOM Div American Mgmt Assn.

Rutgers, J. (2015). Design Thinking Making, OCADU, 2015.

Rutgers, J., Kim, M. S., \& Epp, P. (2015). Unpacking the Concept of Design Thinking Through a Competency-based Curriculum. In EdMedia: World Conference on Educational Media and Technology (pp. 310-321). Association for the Advancement of Computing in Education (AACE).

Sandwith, P. (1993). A hierarchy of management training requirements: The competency domain model. Public Personnel Management, 22(1), 43-62.

Schon, D. A. (1984). The reflective practitioner: How professionals think in action (Vol. 5126). Basic books.

Self, J. A., \& Baek, J. S. (2017). Interdisciplinarity in design education: understanding the undergraduate student experience. International Journal of Technology and Design Education, 27(3), 459-480.

Spencer, L. M., \& Spencer, P. S. M. (2008). Competence at Work models for superior performance. John Wiley \& Sons. 
Strauss, V. (2014). One way to help solve America's major curriculum problem, Washington Post, Feb 24, 2014. Acsessed 02/10/17.

Toohey, S. (1999). Designing courses for higher education. McGraw-Hill Education (UK).Chicago

Watson, P. (2017). Convergence: The Deepest Idea in the Universe, Simon \& Schuster.

West, H., Loftin, C. T., Snyder, C. L. (2017). The Health Professions Educator: A Practical Guide for New and Established Faculty, in The Health Professions Educator: A Practical Guide for New and Established Faculty eds. Hass and Kayingo, Springer Publishing. 
Filename:

Folder:

Template:

Title:

Subject:

Author:

Keywords:

Comments:

Creation Date:

Change Number:

Last Saved On:

Last Saved By:

Total Editing Time:

Last Printed On:

As of Last Complete Print
Fass et al DRS 2018.docx

/Users/lisafass/Library/Containers/com.microsoft.Word/Data/Documents /Users/lisafass/Downloads/DRS2018_PaperTemplateCamera.dotx DRS 2018 Paper Template

Microsoft Office User

2/22/18 3:24:00 PM

2

2/22/18 3:24:00 PM

Microsoft Office User

1 Minute

2/22/18 3:24:00 PM

Number of Words: 6,144 (approx.)

Number of Characters: $\quad 35,021$ (approx.) 